\title{
LOGICIDADE, (IM)PERFEIÇÃO, LIBERDADE, ESPONTANEIDADE: TEMAS CAROS AO DEBATE NA INTERLINGUÍSTICA
}

\author{
Lógica, (Im)Perfección, Libertad, Espontaneidad: Temas Apreciados en el \\ Debate en Interlinguística
}

\author{
Ivan EIDT COLLING ${ }^{1}$ \\ Universidade Federal do Paraná \\ ivanchjo@ufpr.br \\ https://orcid.org/0000-0003-4813-4465
}

\begin{abstract}
RESUMO: A relação entre o plano da expressão e o plano do conteúdo serve como fundamento para uma discussão sobre logicidade, regularidade e perfeição nas línguas. No séc. 17, a movimentação em torno das línguas filosóficas universais promoveu uma tentativa de congruência, de mapeamento conforme entre esses planos, o que implica uma classificação rigorosa de coisas e de noções. Nessas propostas, de concepção apriorística, buscava-se eliminar ambiguidades e dubiedades a fim de que os conceitos ficassem transparentes, límpidos; seu principal objetivo era ajudar a raciocinar. O esperanto, por sua vez, teve início no séc. 19 sob uma perspectiva inteiramente diferente: é planejada a posteriori, concebida como auxiliar para a comunicação de pessoas que não compartilham a mesma língua materna. Com uma história de 133 anos, é atualmente uma língua viva, utilizada por uma comunidade dispersa no mundo. Pretendo apresentar uma visão geral sobre línguas filosóficas e sobre línguas planejadas que enfocam a lógica e contrastar os ideais de perfeição e logicidade existentes nesses projetos com o que se encontra no esperanto. Além disso, pretendo ilustrar como nesta língua se equilibram regularidade e flexibilidade, liberdade, fluidez, com base em elementos de sua morfologia. PALAVRAS-CHAVE: Filosofia da linguagem; Logicidade nas línguas; Línguas filosóficas; Esperanto.
\end{abstract}

\footnotetext{
${ }^{1}$ Membro do grupo de pesquisas Filosofia, Ciência e Tecnologias e coordenador do projeto de extensão Línguas em Diálogo O presente texto é a tradução, com algumas poucas alterações, do artigo publicado na revista JKI - Język, Komunikacja, Informacja (COLLING, 2015b) com base no estudo apresentado na conclusão do Curso de Pós-Graduação em Estudos Interlinguísticos realizado na Universidade Adam Mickiewicz, em Poznań, Polônia, sob a orientação da Profa. Dr-hab. Ilona Koutny.
} 
RESUMEN: La relación entre el plano de la expresión y el plano del contenido sirve como fundamento para una discusión sobre cualidad lógica, regularidad y perfección en las lenguas. En el siglo 17, el trabajo sobre las lenguas filosóficas universales impulsó un intento de mapeo conforme entre esos planos, lo que implica una clasificación rigurosa de cosas y de nociones. En esas propuestas, de concepción apriorística, se buscaba eliminar ambigüedades y equivocaciones para que los conceptos se mostraran transparentes; su principal reto era ayudar a raciocinar. El esperanto, a su vez, tuvo inicio en el siglo 19 desde una perspectiva completamente distinta: es planificada a posteriori, concebida como auxiliar para la comunicación entre personas que no comparten la misma lengua materna. Con una historia de 133 años, es actualmente una lengua viva utilizada por una comunidad dispersa en el mundo. Es mi intención presentar una visión general sobre lenguas filosóficas y sobre lenguas planificadas con énfasis en lógica y contrastar los ideales de perfección y lógica existentes en esos proyectos con aquello que se encuentra en el esperanto. Además, me propongo ilustrar como en esta lengua se equilibran regularidad y flexibilidad, libertad, fluidez, con base en elementos de su morfología. PALABRAS-CLAVE: Filosofía del lenguaje; Cualidad lógica en las lenguas; Lenguas filosóficas; Esperanto.

RESUMO: La rilato inter esprimtavolo kaj enhavtavolo estas konvena fundamento por aliri la temon pri logikeco, reguleco kaj perfekteco en lingvoj. En la dek-sepa jarcento, la intensa laboro super universalaj filozofiaj lingvoj instigis al klopodoj kongruigi tiujn tavolojn, estigi konforman bildigon inter ili, kio implicas rigoran klasifikadon de ajoj kaj nocioj. En tiaj proponoj, kies konceptado estis apriora, oni strebis forigi ambiguecon kaj dubsencecon, por ke konceptoj estu travideblaj, puraj; ilia ĉefa celo estis helpi rezonadi. Esperanto, siavice, estis iniciatita en la dek-naŭa jarcento laŭ tute alia perspektivo: ĝi estis aposteriore planita, elpensita kiel helpilo por komunikado inter homoj, kiuj ne kunhavas la saman denaskan lingvon. Havante 133-jaran historion, ĝi estas nuntempe vivanta lingvo, uzata de komunumo disa en la mondo. Mi intencas prezenti generalan rigardon pri filozofiaj lingvoj kaj planlingvoj, kiuj enfokusigas logikon, kaj kontrastigi la idealojn pri perfekteco kaj logikeco enestantajn en tiaj projektoj kun tio, kio trovighas en Esperanto. Cetere, mi prezentas, kiel en ĉi tiu lingvo estas en ekvilibro reguleco kaj fleksebleco, libereco, flueco, surbaze de elementoj de ties morfologio. ŜLOSILVORTOJ: Lingvofilozofio; Logikeco en lingvoj; Filozofiaj lingvoj; Esperanto. 


\section{INTRODUÇÃO}

A partir de comentários e noções do senso comum, apresento algumas ponderações sobre conceitos como prefeição e logicidade aplicados às línguas, em especial às planejadas, bem como sobre o conceito de língua natural. Uma maneira de se entender a busca de "perfeição" nesse campo consiste em examinar o esforço de conformação entre expressão e conteúdo, conformação essa que, no entanto, redundaria em ruídos e imperfeições na comunicação. Com relação à logicidade, o que muitas vezes as pessoas têm em mente é, de fato, regularidade, posto que há lógica por trás de qualquer língua efetivamente usada por um grupo de pessoas. Um rigor extremo, um engessamento dos recursos de expressão (nos moldes de uma linguagem de programação) concorre para reduzir a expressividade e a espontaneidade e faz com que os falantes não encontrem o espaço de liberdade necessário para exteriorizar as incertezas, imprecisões e nebulosidades da vida. Acredito ser o balanço entre rigor e flexibilidade um dos motivos do sucesso do esperanto, usado sem interrupção há 133 anos por uma comunidade definida por Wood (apud KOUTNY, 2015b, p. 44) como aterritorial, não étnica e na qual se ingressa de forma voluntária.

\section{PERFEIÇÃO, LOGICIDADE, LÍNGUAS IDEAIS, IDEAIS LINGUÍSTICOS}

São recorrentes comentários sobre logicidade e perfeição em línguas. Trata-se, em geral, de opiniões baseadas no senso comum. Provavelmente no campo da interlinguística a frequência e a assertividade com que tais comentários são emitidos aumentem bastante, uma vez que proponentes de línguas planejadas podem justamente apresentar como uma das premissas de suas elaborações a adesão mais ou menos estrita a postulados lógicos, e na classificação de línguas planejadas existe inclusive uma categoria dedicada às línguas lógicas (loglangs), cujo objetivo é facilitar a lógica ou evitar ilogicidades (ROSENFELDER, 2012, p. 48); o representante mais conhecido desse grupo é o lojban.

Apresento a seguir alguns dos comentários que coletei ao longo do tempo.

a) "O latim é lógico, matemático" (professor brasileiro da área de engenharia, ao comentar o sistema de declinação do latim);

b) "O esperanto é certamente uma língua interessante; ele funciona como a matemática" (estudante brasileiro de engenharia elétrica);

c) "Um sistema completamente ilógico" (professor alemão, sobre o sistema de declinação da língua alemã); 
d) "O português não é lógico; isso está errado e deveria ser corrigido!" (estudante de Letras, filho de pais brasileiros, que nasceu e cresceu nos Estados Unidos; sua crítica se refere à dupla negação, que é usada em português, mas também em espanhol, francês e polonês... mas não no inglês formal);

e) “Línguas não são lógicas”(estudante brasileiro, doutorando em linguística).

Nessas afirmações duas tendências principais podem ser encontradas: um idealismo com relação a línguas com as quais a pessoa não tem muita experiência: o estudante em (b) não é falante de esperanto, e a experiência do professor em (a) limita-se a textos escritos em latim, com os quais tem grande habilidade. A outra direção talvez possa ser denonimada consciência do caos, advinda após a aquisição de conhecimento sobre várias línguas e estabelecimento de comparações entre elas; diferentes abordagens são possíveis: minha língua não é lógica (c), a do outro não é lógica e - com um sentimento de superioridade - a minha pode ser um modelo para melhorar a do outro (d), nenhuma língua é lógica (e).

De fato, o latim alimenta um idealismo multifacetado. Em razão da distância entre a gramática normativa e as variantes do português faladas no Brasil, é bastante frequente entre brasileiros a ideia de que aqui muitos não falam bem o português (mesmo sendo falantes nativos...); algumas pessoas acreditam que para melhorar essa situação o ensino do latim deveria ser reintroduzido no sistema educacional ${ }^{2}$. Outra ideia que subsiste é a de que "as línguas neolatinas surgiram por causa da ignorância de povos que não foram capazes de aprender adequadamente a gramática latina", então elas representam uma espécie de degeneração e de alguma forma aquela língua clássica deveria ser revigorada, pois "funciona perfeitamente no âmbito da Igreja Católica Romana". Ainda que haja uma comunidade que a cultiva, e reluto em lhe atribuir o epíteto 'morto', "o latim tem hoje reduzidas chances de sobreviver na Igreja Católica. A verdade pura e simples é que muitos, muitíssimos bispos já não são capazes de falá-lo" (latinista-chefe do Vaticano, Abade Carlo Egger em artigo de James Meek, 1999, apud MATTHIAS, 2003, p. 63).

Também o hebraico ocupou posição privilegiada na cultura europeia; pensava-se que teria relação com a língua pré-babélica, adâmica, com implicações místicas e mágicas. A compreensão de que há uma família indo-europeia, que inclui também o sânscrito e o persa, retirou o hebraico do foco nos séculos 18 e 19 (com a ascensão do mito sobre cultura ariana, o que também infelizmente teve suas consequências políticas na história posterior) (ECO, 1994, p. 95).

\footnotetext{
${ }^{2}$ A obrigatoriedade do ensino do latim foi retirada no Brasil em 1961 (PICANÇO, 2003, p. 42).

Revista X, v. 15, n. 6, p. 793-817, 2020. 
Não causa admiração o fato de o latim ocupar tal posição idealizada. Ele foi a interlíngua europeia até o séc. 17, quando sua hegemonia começou a decair. Evidentemente, um fenômeno como esse ocorre em consequência de mudanças sociais, políticas e econômicas (e especificamente neste contexto ciência e religião desempenharam papel importante). Elas desafiam as pessoas, causam insegurança e as instigam a buscar um novo estado de equilíbrio, o qual pode ser promovido por meio de uma nova convenção de aceitação geral: "a ideia de desenvolver uma nova língua universal para substituir o latim originou-se em parte na nostalgia da cristandade internacional" (CLAUSS, 1982 apud MAAT, 2004, p. 9). Esse ideal linguístico floresceu não somente na cultura europeia e nas regiões sob sua influência: "a utopia de uma língua perfeita foi uma obsessão não somente na cultura europeia. O tema da confusão das línguas e as tentativas para encontrar uma solução para ela por meio da descoberta ou do desenvolvimento de uma língua comum a todo o gênero humano atravessa a história de todas as culturas" (ECO, 1994, p. 16).

Os ideais linguísticos, então, oscilam entre perfeição, talvez com aspectos transcendentais, precisão, logicidade matemática, passando pela gramática normativa, uma vez que a norma prescritiva é também um ideal (BAGNO, 2009, p. 36-39) - como consequência, ninguém faz uso dessa norma durante todo o tempo.

Considerações sobre perfeição e racionalidade estão presentes na seguinte declaração do Prof. Evaldo Pauli (1925-2014), professor de filosofia, presidente da Filozofia Asocio Tutmonda, Associação Internacional dos Filósofos Esperantistas e editor da revista filosófica Simpozio (destaco que, neste texto, ele se refere à língua como se ainda fosse um projeto):

Em 1946, aos 21 anos, [...] aconteceu minha adesão ao projeto da Língua Internacional Esperanto. Esta minha adesão poderia ter acontecido mais cedo, se os programas de ensino de então houvessem estado mais atentos na informação que devem dar aos estudantes, instruindo-os de que uma língua também pode ser projetada racionalmente e tornada mais perfeita [...].

[...] Considerando finalmente o princípio de que a ciência deve conduzir ao mais perfeito, importa pôr-nos também a caminho de uma língua perfeita. [...] Minha adesão ao Esperanto se deu exatamente por este princípio, a busca do mais perfeito em tudo, inclusive no quadro da língua. $O$ engenheiro estuda não apenas para consertar máquinas preexistentes, mas também para inventar máquinas mais perfeitas. (PAULI, 1995, p. 101-102). 
Em 1924, 42 cientistas da Académie des sciences francesa declararam que o esperanto é "uma obra-prima de lógica e simplicidade" (MASSON, 2008; FRANCINI, 1978). Andreo Cseh [András Gergely János Cseh, 1895-1979], que se notabilizou como professor de esperanto a partir de 1927 utilizando o método direto - conhecido no meio esperantista como Cseh-metodo ou ce-metodo -, faz uma afirmação hiperbólica, após a apresentação das regras de formação do plural: "Como você vê, em esperanto não existe gramática. Somente lógica. É por essa razão que nós o aprendemos fácil e rapidamente. E com prazer. Você não precisa de um livro, porque a lógica está em sua cabeça" (texto de 1929, IEI 1992, p. 11).

No ensaio clássico Essência e futuro da ideia de uma língua internacional, de 1900, podem ser encontrados algumas opiniões e ideais de Zamenhof:

De onde provém esta facilidade incrível da língua internacional? Toda língua natural é construída ao sabor do acaso, pelos caminhos do acúmulo das circunstâncias mais diversas e ocasionais; não há a colaboração de nenhuma lógica, de nenhum plano definido, mas simplesmente do uso. [...] Já anteriormente, por isso, podia-se dizer que um sistema de sons para a expressão do pensamento que fosse criado pela inteligência humana, conscientemente e segundo leis severamente definidas e lógicas, deveria ser muito, mas muito mais fácil do que um sistema de sons que fosse construído ao acaso e inconscientemente. (ZAMENHOF, 1988, p. 26; grifos presentes no original em esperanto).

A segunda qualidade distintiva de uma língua artificial é a sua perfeição, que consiste numa precisão e flexibilidades matemáticas, numa riqueza infinita. [...]

Que uma língua artificial não apenas pode, como deve ser mais perfeita do que as línguas naturais, é a conclusão a que chega qualquer um que considerar o seguinte: todas as línguas naturais foram construídas através de um processo no qual um repetia o que ouvia de outros; nenhuma lógica, nenhuma decisão consciente da inteligência humana teve aqui qualquer força. (Ibidem, p. 29-30, grifos presentes no original).

[...] toda língua natural se estrutura não sobre a lógica, mas sobre o "a gente diz assim" ou "a gente não diz isso". [...] Mas numa língua artificial, conscientemente fundada sobre as severas (que não permitem nenhuma exceção ou arbítrio) leis do pensamento, nada semelhante pode ter lugar. (ZAMENHOF, 1988, p. 30-31).

Zamenhof e Pauli claramente absorveram a promessa modernista de que a razão e a ciência trariam um futuro maravilhoso para a humanidade (COLLING, 2012b). Como resultado das catástrofes sociais, políticas, ecológicas decorrentes dessa maneira de 
pensar, na pós-modernidade as pessoas tendem a duvidar dessa promessa, imersas que estão em soluções tecnológicas e 'realidade virtual' (uma tentativa de criar algo melhor que a 'realidade real'?), soluções essas fortemente ancoradas em aplicação de lógica extrema (bits, bytes, álgebra Booleana).

Outro ponto chama a atenção no texto: Zamenhof usa a expressão lingvo arta em contraste com lingvo natura. Na tradução ao português, perde-se o sentido positivo evocado no texto original pela proximidade de arta com a ideia de "artístico", uma vez que na linguagem corrente não está presente a ligação etimológica de "artificial” com a noção "feito com arte". Esse contraste, no entanto, não é hoje aceito por muitos esperantistas (p. ex. CHERPILLOD, 2006; Idem, s.d.; PASSINI, 2008, p. 69-71), que preferem utilizar "língua étnica" ou "nacional" em contraste com "língua planejada", usando o termo proposto por Eugen Wüster em 1931 (BARANDOVSKÁ-FRANK, 2020, p. 4). Registro ainda que, em inglês, é frequente a expressão "língua construída" (constructed language) ou seu acrônimo CONLANG:

Os termos "língua construída" (constructed language) e seu conceito
complementar, "língua étnica" e "língua nacional" estão substituindo
a terminologia anteriormente usada para essas línguas, isto é, línguas
"artificiais" e "naturais". Quem advoga a nova terminologia destaca
que nenhuma língua é "natural" no sentido em que uma árvore, uma
pedra ou um animal é natural e que, pelo contrário, todas as línguas
étnicas e/ou nacionais, sendo produtos da mente e da cultura humanas,
são essencialmente artificiais. (HAGLER, 1971, p. 40-41)3.

Em minha opinião, entretanto, o particípio “construída" não reflete o fenômeno de construção coletiva permanente que pode ter lugar caso ocorra um processo de socialização - o exemplo mais contundente é o próprio esperanto, que conta 133 anos de uso contínuo, e tal construção coletiva estava prevista por Zamenhof: “...a língua internacional deve viver, crescer e progredir segundo as mesmas regras segundo as quais são elaboradas todas as línguas vivas” (ZAMENHOF, 1888, “Aldono”, p. 7), que por esse motivo preferia ser chamado de "iniciador" do esperanto, e não seu "criador" (ZAMENHOF, 1888, p. 8).

Para mim, a dicotomia natural / artificial constitui-se em outra idealização, que simplifica e oculta a complexidade do fenômeno das línguas. Claude Piron (2007, p. 154) afirma que o conceito "natural" é relativo, e cita Rabelais: "É um erro dizer que nós temos uma linguagem natural: as línguas existem por instituição arbitrária e convenção dos povos". Para John Wilkins (citações de 1668 e 1641 apud MAAT, 2004, p. 150), "É

\footnotetext{
${ }^{3}$ Os textos para os quais não há menção de tradutor foram traduzidos por mim.
} 
suficientemente evidente que nenhuma língua é natural para a humanidade"; "Línguas são tão naturais para nós quanto o são as outras Artes e Ciências. O Ser Humano nasce sem nenhuma delas, no entanto capaz de todas elas". Raciocínio semelhante é apresentado por Jouko Lindstedt (2006, p. 49):

Evidentemente o termo "língua natural" por si mesmo não deixa de ser problemático, pois todas as línguas humanas são convenções sociais, não fenômenos biológicos - o que é biologicamente determinado é somente a capacidade geral de a criança aprender uma ou várias dessas línguas sociais.

Nesse contexto, conforme Ida Stria (2015, p. 32), “[...] o esperanto, ainda que 'geneticamente' artificial, é em muitos aspectos indistinguível das línguas étnicas naturais”. Para Ilona Koutny (2015a), não se pode estabelecer uma classificação binária entre "naturais" e "planejadas", mas antes se deve pensar em um contínuo entre esses dois polos. A autora também propõe uma caracterização tipológica para encontrar o lugar do esperanto entre as línguas ditas naturais (KOUTNY, 2015b).

$\mathrm{Na}$ realidade, cada língua étnica é produto da inteligência humana. Seu desenvolvimento aconteceu e acontece de acordo com leis lógicas; do contrário, não haveria compreensão recíproca entre seus falantes. Essas leis nem sempre foram ou são estritamente definidas. Não se pode, contudo, afirmar que nesse processo não houve nenhuma lógica, nenhuma decisão consciente da inteligência humana. Além disso, há apenas uma? ( $A$ lógica, com artigo definido, aparece nas citações anteriores tanto de Cseh como de Zamenhof.) O que significa língua perfeita? É fato que se for "perfeita" não há gramática, há somente lógica pura? Em uma língua planejada que ascende ao status de viva, logicidade e a precisão matemática são observadas de maneira inflexível, ou o hábito e a convenção também desempenham um papel? Não há nela arbitrariedades ou exceções?

\section{PLANO DA EXPRESSÃO, PLANO DO CONTEÚDO, REALIDADE}

De acordo com Louis Hjelmslev (segundo ECO, 1994, p. 31-32) a língua consiste em dois planos: o plano da expressão (os recursos usados para expressar: léxico, fonologia, morfologia, sintaxe) e o plano do conteúdo (tudo o que pode ser expresso). Em cada plano há forma e substância. A relação entre o plano da expressão e o plano do conteúdo se estabelece por meio de unidades maiores (unidades lexicais), não por fonemas isolados: em esperanto a sequência de sons ['ho.mo], com o significado de 'ser humano' (semelhante 
ao alemão Mensch, polonês człowiek) é compreensível somente quando tomado na íntegra - não há um significado especial atribuído a cada fonema de modo que a palavra não pode ser decomposta e compreendida por sua soma $/ \mathrm{h} /+/ \mathrm{o} /+/ \mathrm{m} /+/ \mathrm{o} /$. (Ou, mais precisamente, ela consiste em dois morfemas: hom-, morfema lexical portador do sentido e que não pode ser analisado em partes menores, e $-o$, morfema gramatical que aponta para a classe de palavras "substantivo"). É por essa razão que a mudança em um simples som pode acarretar uma enorme diferença no significado: considerem-se, como exemplo: homo ['ho.mo], domo ['do.mo], komo ['ko.mo], vomo ['vo.mo], pomo ['po.mo], nomo ['no.mo] (respectivamente: 'ser humano', 'casa', 'vírgula', 'vômito', 'maçã', 'nome'); ou então procure-se alguma correlação na mudança de significado que ocorre entre homo / horo ('ser humano' / 'hora') com aquela entre komo / koro ('vírgula' / 'coração'), ainda que se tenha efetuado a mesma mudança $/ \mathrm{m} / \rightarrow / \mathrm{r} /$ na mesma posição em sequências de quatro fonemas. Em outras palavras, o relacionamento entre a forma do conteúdo e a forma da expressão é arbitrário. Hjelmslev chama isso de sistema não conforme (segundo ECO, 1994, p. 33).

A nomenclatura usada pelo linguista dinamarquês pode ser melhor entendida se considerarmos que no ponto $\left(x_{0}, y_{0}\right)$ no plano $x y$ ocorre a intersecção de duas curvas, $C_{1} \mathrm{e}$ $C_{2}$, que nesse ponto fazem entre si o ângulo $\alpha$. Se for feito o mapeamento das curvas no plano $u v$, de modo que $\left(u_{0}, v_{0}\right), C^{\prime}{ }_{1}$ e $C^{\prime}{ }_{2}$ são respectivamente as imagens de $\left(x_{0}, y_{0}\right), C_{1}$ e $C_{2}$, e o ângulo $\alpha$ se mantiver o mesmo (em valor e em sentido, conforme mostrado na fig. 1), diz-se que a transformação é conforme (SPIEGEL, 1964, p. 200-201). Na fig. 2 procuro ilustrar como se estabelecem as ligações entre o plano da expressão e o plano do conteúdo - a linha imaginária unindo os pontos $\mathrm{A}, \mathrm{B}$ e $\mathrm{C}$ não tem a mesma forma que a linha que passa pelos pontos A', B' e C'.

FIGURA 1 - MAPEAMENTO CONFORME: o ângulo $\alpha$, presente no plano $x y$, mantém-se com o mesmo valor e o mesmo sentido no plano $u v$.

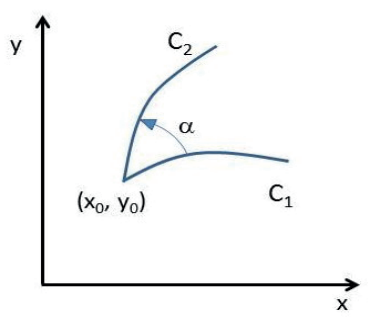

(a)

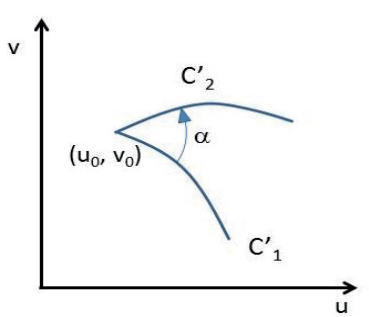

(b)

FONTE: Adaptado de SPIEGEL, 1964, p. 201. 
FIGURA 2 - PLANO DA EXPRESSÃO E PLANO DO CONTEÚDO.

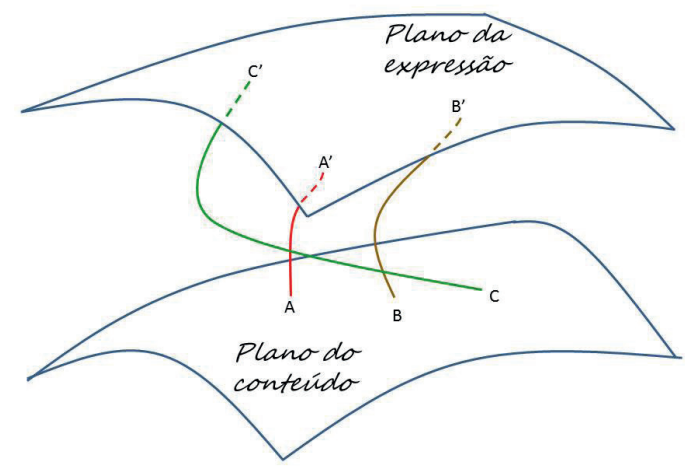

FONTE: O autor.

\section{A BUSCA DA PERFEIÇÃO: LÍNGUAS FILOSÓFICAS, CARACTERE REAL}

$\mathrm{Na}$ época do Humanismo na Europa houve um grande interesse pela elaboração de uma língua filosófica universal, que deveria ser um "espelho das coisas" (BARANDOVSKÁ-FRANK, s.d.). Seu principal objetivo não era servir para a comunicação (uma vez que o latim cumpria essa função entre pessoas educadas), mas ajudar a pensar. Em 1623, Francis Bacon propôs que uma língua perfeita fosse elaborada a partir da comparação entre as existentes, usando as vantagens de cada uma delas; tratase de uma abordagem a posteriori. Em 1629, entretanto, em carta a seu amigo Marin Mersenne, Descartes escreveu sobre a definição de "uma ordem para cada pensamento que pode entrar na mente humana", similar à ordem que existe para os números: para compreender ' 1629 ' não precisamos ter anteriormente pensado sobre '1628', '1627': as regras da aritmética nos permitem chegar imediatamente a seu significado, a seu valor. (ZILAH, 1983; DESCARTES, 1987; COLLING, 2012a).

Conhecer a ordem dos pensamentos implica uma detalhada classificação das noções, a qual pode se constituir em base para a elaboração de um esquema a priori. Seria um sistema construído

sobre uma rigorosa base lógica. A língua comum era para Descartes uma chave lógica, por meio da qual se poderiam classificar em uma ordem lógica as realidades do mundo e todas as relações entre elas. A aparente infinitude das ideias e noções deveria ser reduzida a um 
número limitado das unidades mais gerais. Isso poderia ser feito pelo método similar àquele por meio do qual se forma uma quantidade ilimitada de numerais usando somente dez algarismos. (DULIĈENKO, 2006, p. 48).

É oportuno lermos também o comentário de Eugène de Zilah sobre o assunto:

segundo meu conhecimento, essa carta é a única contribuição de Descartes ao desenvolvimento da ideia de uma língua universal. Tal língua ele próprio jamais tentou criar. [...] Ele sonhava com uma língua universal totalmente racional. Não devemos confundir a ideia de uma língua universal, filosófica, com a de uma língua internacional. (ZILAH, 1983, p. 14).

Apesar da advertência de Descartes de que a implementação de uma língua filosófica, ainda que possível, implicaria "grandes mudanças na ordem das coisas", muitos intelectuais seguiram a abordagem apriorística (Wilkins, Dalgarno, Leibniz, Boyle, Aubrey, Hooke, Lodwick, Wallis, Mersenne, Comenius, Campanella, Kinner, Urquhart, Newton, Ampère, Kircher - segundo MAAT, 2004, p. 23, 28, 256; DULIĈENKO, 2006, p. 48-53; ECO, 1994). O trabalho de classificação necessário para organizar os pensamentos foi baseado, em maior ou menor grau, nas categorias de Aristóteles.

Em sua obra De dignitate et augmentis scientiarum, de 1623, Bacon usa a expressão "caractere real" (real character), para indicar um signo que apontasse diretamente a coisas e noções, ancorado na realidade, sem o recurso da palavra. Em 1668 a expressão aparece no título do livro de John Wilkins, An essay towards a real character and a philosophical language, e foi usada por outros estudiosos, como Leibniz. O objetivo de uma língua filosófica é "eliminar ambiguidades, dubiedades, absurdos das línguas naturais" (ALBANI; BUONARROTI, 2011, p. 146). Segundo Jones (1951 [1932] apud MAAT, 2004, p. 8), os cientistas do séc. 17 suspeitavam das línguas, associadas com "a ciência antiga, que parecia depender mais de palavras do que da natureza", e porque "tendem a obscurecer ao invés de descrever realidades". Essa suspeição encontra-se também em Locke; ele sugere que nos acostumemos a separar nossas contemplações e raciocínios das palavras (LOCKE, 1890 - texto de 1690).

Pode-se imaginar que as superfícies da fig. 2 sejam peças de tecido; a conformação dos planos seria como a tentativa de 'costurar' uma à outra ou, em um esforço mais extremo, ambas deveriam 'cair' sobre a realidade e tomar sua forma. Essa faceta da perfeição, uma congruência exata entre língua e realidade, lembra o trabalho dos cartógrafos do conto de Borges (1974), que construíram um mapa do império tão grande quanto o próprio império, 
o que depois provou ser inútil. Modelos físicos, por exemplo, são em geral descrições simplificadas de fenômenos, desenvolvidas até o nível de detalhamento necessário para o problema considerado. Em uma descrição nem tudo importa, e também é impossível avaliar absolutamente todos os detalhes em minúcias.

Vejo alguns esforços de Leibniz como representativos dessa busca de extrema conformação das superfícies com a realidade (ou, mais precisamente, com o conhecimento da realidade). Leibniz considerava possível a definição do 'alfabeto dos pensamentos humanos', isto é, os termos deveriam ser analisados em partes menores, que por sua vez seriam novamente analisadas, até o ponto em que somente existissem "partes simples, isto é, termos indefiníveis" (MAAT, 2004, p. 278), posto que, para ele, definir é analisar em partes menores. Em sua doutrina - atomismo -, os termos fundamentais funcionam como tijolos; em função dos problemas encontrados na busca pelas primitivas, pelos tijolos básicos, considera-os como postulados e principia a trabalhar na 'álgebra dos pensamentos humanos', com o propósito de descobrir, por meio de cálculo, se uma sentença é verdadeira ou falsa. Sua esperança é a de que algum dia "raciocínio e cálculo serão a mesma coisa" (apud MAAT, 2004, p. 323). Em um de seus trabalhos, o filósofo associa as primitivas com os números primos, enquanto as derivadas são expressas como produtos. Eco (1994, p. 226-232) apresenta um exemplo: se 'animal' for representado por '2', 'racional' por '3', 'ser humano' é '6'; um 'macaco' ('10') é um 'animal' ( $10 / 2=5$, exatamente), mas não 'racional' (10/3 não é inteiro). Uma análise matemática possibilitaria a interpretação imediata: um sujeito contém seus predicados, de modo que qualquer asserção envolvendo esse sujeito pode ser matematicamente verificada (um dos princípios da teoria analítica da verdade). Relacionando-se os algarismos de 1 a 9 com consoantes e as potências de dez com vogais, as quantidades resultantes podem ser pronunciadas. Há certo grau de arbitrariedade na definição das primitivas (que provavelmente dependeriam da 'verdadeira filosofia', no dizer de Descartes), mas os conceitos derivados refletem seus constituintes e obedecem a leis da álgebra, e dessa maneira os planos 'tomam a forma' da realidade. Uma imponente construção teórica, mas falta definir os tijolos. Leibniz (1646-1716) jamais perdeu o otimismo com relação a exequibilidade de seus projetos (MAAT, 2004, p. 390).

Não tão extrema, mais arbitrária, com adesão entre os planos, mas não tanta aderência à realidade (ou ao conhecimento que dela se tem), é a proposta publicada em 1668 por John Wilkins, fundador e primeiro secretário da Sociedade Real (Royal Society). Sua classificação segue a hierarquia aristotélica, conforme apresentada por Porfírio (PORFIRIO, 1983): gênero - diferença - espécie. Como exemplo, zibi é analisado como (zi)+(b)+(i). Zi representa o gênero "animal", $b$ é a primeira diferença dentro do 
gênero, de modo que zib é "animal de pata inteira", e finalmente $i$ é a quarta espécie, que Wilkins definiu como sendo "elefante" (ECO, 1994, p. 204-205; MAAT, 2004, p. 218222). Classificar os animais segundo o critério pata inteira / pata fendida é um critério de Wilkins, assim como a decisão de que o elefante é a quarta espécie dentro desse subgênero. Os símbolos associados a esses conceitos são mostrados na fig. 3. O segmento à esquerda nas figs. $3 \mathrm{~b}$ e $3 \mathrm{c}$ marca a diferença, denotada conforme o ângulo (crescente em sentido anti-horário) e o tamanho; de forma semelhante, o segmento à direita na fig. 3c indica a espécie conforme o ângulo (crescente em sentido horário) e o tamanho.

Outro exemplo de um esquema a priori é Ro, proposta em 1906/1908 por Edward Powell Foster. A letra inicial $b$ indica 'existência, matéria'; seguem algumas palavras derivadas (DREZEN, 1991, p. 201-202):

$$
\begin{array}{ll}
\text { bod } & - \text { universo; } \\
\text { bodac } & - \text { céu; } \\
\text { bodal } & - \text { planeta; } \\
\text { bodala } & - \text { planeta Mercúrio; } \\
\text { bodam } & - \text { lua; } \\
\text { bodar } & - \text { estrela; } \\
\text { bodas } & - \text { sol. }
\end{array}
$$

E os numerais básicos (LARGE, 1987, p. 176):

$$
\begin{gathered}
1 \text { - zab; } \\
2 \text { - zac; } \\
3 \text { - zad; } \\
4 \text { - zaf; } \\
5 \text { - zag; } \\
6 \text { - zal; } \\
7 \text { - zam; } \\
8 \text { - zaq; } \\
9 \text { - zar; } \\
10 \text { - zax. }
\end{gathered}
$$


FIGURA 3 - IDEOGRAMAS DE WILKINS: a) Zi ('animal'); b) Zib ('animal de pata inteira); c) Zibi ('elefante).

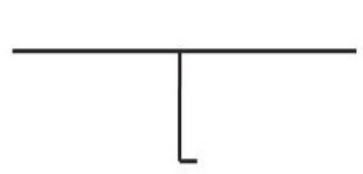

(a)

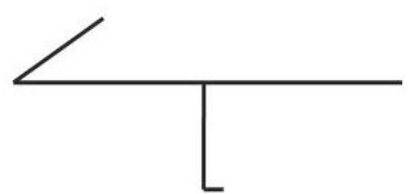

(b)

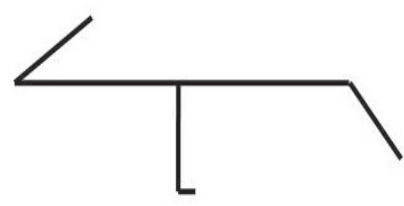

(c)

FONTE: Adaptado de MAAT, 2004, p. 218.

Sem dúvida, os exemplos acima obedecem a critérios lógicos. Esse tipo de esquema torna possível a compreensão do conceito geral, mesmo que o significado preciso de uma palavra não tenha ainda sido aprendido (por exemplo, se alguém ouve a palavra zibi e consegue decodificar somente $z i$, isso é suficiente para que saiba que se trata de um animal - conforme comenta Maat, 2004, p. 224-225). A função 'lógica' da língua é, no entanto, comunicação, e o uso de expressões similares para conceitos similares é um meio eficaz para trazer confusão - como se pode imaginar se alguém quiser informar a outra pessoa um número de telefone em Ro! Em línguas étnicas, a estratégia para lidar com palavras semelhantes ou homônimos é que geralmente elas têm sentidos bastante distintos; em outras palavras: regiões próximas no plano da expressão apontam para regiões distantes umas das outras no plano do conteúdo. Essa estratégia é também usada nas planejadas a posteriori. A não conformidade dos planos ajuda os falantes a apreender o sentido das palavras de acordo com o contexto.

É sabido que as línguas filosóficas não foram concebidas com a intenção de servir para a comunicação diária; sua finalidade primária é ajudar a pensar e a raciocinar e aumentar as potencialidades intelectuais de seus usuários. Não se deve, contudo, supor que seus usuários jamais tentassem se comunicar por meio dela. É também possível imaginar-se um debate entre filósofos e cientistas: "afirmava-se que o famoso químico Robert Boyle, um dos fundadores da Sociedade Real, falava esta língua [aquela proposta por Wilkins]" (DULIĈENKO, 2004, p. 50). Nessa situação, os mal-entendidos poderiam surgir de suas características, paradoxalmente das próprias características pensadas para conformá-la à realidade, as palavras às coisas.

Tendo sido concebidos como tipos de línguas ou códigos de trabalho, esses esquemas não somente não são destinados ao uso cotidiano; eles são na verdade incompletos para 
expressar a plenitude da experiência humana. Seus proponentes buscaram seguir critérios objetivos, científicos, de modo que há pouco espaço para elementos míticos, instintivos ou intuitivos: Wilkins, por exemplo, não inclui em seu léxico 'animais ficcionais', como sereias, unicórnios - se necessário, seriam transcritos como nomes a partir das palavras correspondentes em inglês (MAAT, 2004, p. 183). Esses elementos, no entanto, também se fundem em um mosaico holístico, colorido de percepções que a língua deveria ser capaz de expressar. Por outro lado, a ciência não é tão 'pura' e isenta de mitos. Além disso, um sistema racional, científico não permite a seus usuários gracejarem...: “[...] nunca pode haver surpresas na lógica" (WITTGENSTEIN, 2010, p. 259, § 6.1251).

É interessante observar-se que o próprio Wilkins tinha ciência das dificuldades da busca ontológica pelas essências e suas definições imutáveis, e procurou itens que lhe pareciam imunes de mudanças, os quais confeririam estabilidade a sua proposta:

Ele não somente se cala a respeito do que se poderia esperar que dissesse caso considerasse que as essências estão ainda por serem descobertas, mas a afirmação de que "as pessoas deveriam estar satisfeitas" com descrições de propriedades observáveis claramente sugere que antevia como permanente a ignorância humana sobre as essências. Além disso, temos o testemunho de Dalgarno [...] de que Wilkins estava inclinado a crer que essas "essências" não existem, e que as considerou de forma definitiva como incognoscíveis. A confiança em propriedades observáveis em lugar de propriedades essenciais está também completamente de acordo com as premissas da ciência experimental conduzida e promovida por Wilkins e seus colegas na Sociedade Real. (MAAT, 2004, p. 172).

É muito provável que Wilkins tenha omitido de suas tabelas todos os tipos de coisas que mudam constantemente, bem como coisas das quais novas variedades são constantemente produzidas, justamente porque almejava que as raízes denotassem somente um núcleo de itens permanentes. (MAAT, 2004, p. 224).

Obviamente, ele não poderia ter ultrapassado os limites do conhecimento de seu tempo e espaço: assim, designou uma posição especial aos quatro elementos (terra, fogo, água e ar) - não sem mencionar que "as pessoas agora começam a duvidar" da validade da teoria dos quatro elementos.

Wilkins, bem como outros filósofos, teve sucesso no estabelecimento de sua proposta, que depois se tornou obsoleta em função dos desenvolvimentos na ciência e na sociedade. $\mathrm{O}$ intento de Leibniz, porém, era por demais pretensioso: a álgebra dos pensamentos humanos e a teoria analítica da verdade não são factíveis - o que é um alívio para nós, seres pensantes cuja criatividade não pode ser determinada matematicamente ou 
limitada pela lógica.

A compreensão atual é que a verdade é relativa e plural, a ciência é uma construção humana e é impossível descrever completamente a realidade sendo ao mesmo tempo parte dessa realidade; entende-se então que uma língua filosófica poderia somente refletir pontos de vista com maior ou menor aceitação geral no tempo e no espaço, não podendo assim ser completamente elaborada - talvez Descartes tivesse isso em mente quando escreveu que seu desenvolvimento depende da 'verdadeira filosofia' (DESCARTES, 1987). Se admitimos que a ciência fornece a melhor descrição da realidade, temos forçosamente de estar conscientes de que ela jamais a fornece de forma definitiva. A língua poderia no máximo refletir (e refletir a duras penas!) o estado da arte em dado momento.

Ela também não poderia ser atualizada - as características dinâmicas da ciência implicam a prontidão para lidar com mudanças - algumas delas bastante radicais - a qualquer momento. Idealmente, a ciência está aberta a dúvidas e está baseada na construção participativa constante. Uma língua que é 'espelho das coisas' - ou espelho do conhecimento que se tem das coisas -, baseada na descrição científica, deve ter um léxico capaz de refletir essa descrição e propenso a mudar em função de mudanças nessa descrição, o que provavelmente seria tarefa de uma comissão de intelectuais e cientistas dos mais diversos campos. Por exemplo, ao tempo de Wilkins, Plutão não era conhecido; posteriormente descoberto e classificado como planeta, teria de ser representado por um caractere, o qual, sendo um 'caractere real', no séc. 21 deveria sofrer modificação, após a reclassificação daquele corpo celeste como planeta anão. De forma semelhante, há conceitos como flogisto, calórico e éter, que perderam a validade, o que deveria estar registrado em seus respectivos caracteres e nas pronúncias a eles associadas. Se hoje fossem feitas propostas de palavras, provavelmente mereceriam caracteres específicos conceitos como onda-partícula, matéria-energia, espaço-tempo...

Em função dessa dinâmica, tarefa hercúlea seria manter-se a par de tantas atualizações, logo muito difícil - impossível! - seria atingir/manter a fluência na língua.

\section{ESPERANTO: ESTABELECENDO UM COMPROMISSO ENTRE REGULA- RIDADE E FLEXIBILIDADE}

A direção apriorística, inspirada na carta de Descartes, foi dominante por dois séculos. Uma exceção deve ser mencionada: Juraj Križanić (1617/1618-1683) e sua língua pan-eslávica a posteriori (DULIĈENKO, 2006, p. 54-60). Ainda que esquemas apriorísticos continuem sendo propostos a partir do séc. 19, é nesta época que a abordagem a posteriori se torna mais forte, impulsionada pela necessidade de comunicação, pelo 
desenvolvimento do comércio e dos meios de transporte (PASSINI, 2008, p. 46). A língua planejada a posteriori de maior sucesso é o esperanto, cujas bases foram lançadas em 1887 em Varsóvia por Luís Lázaro Zamenhof (Ludwik Łazarz, Ludwik Lejzer, Ludoviko Lazaro Zamenhof, 1859-1917). Efetivamente falada em uma comunidade transnacional em escala mundial, com falantes nativos e expressões culturais próprias, como qualquer língua viva tem seu desenvolvimento promovido pelos falantes de acordo com suas necessidades em situações comunicativas.

A característica morfológica mais evidente do esperanto são seus morfemas gramaticas; apresento uma lista básica no quadro 1. Todos os exemplos dados anteriormente terminam em -o, pois são substantivos. A classe gramatical é alterada pela mudança da terminação: domo, doma, dome ('casa', 'doméstico', 'em casa'); nomo, nomi ('nome', 'nomear'); o verbo nomi é conjugado no indicativo nomas, nomis, nomos (respectivamente, indicativo presente, passado e futuro, para todas as pessoas). Esse sistema funciona com extrema regularidade no esperanto, e se aplica também a neologismos, como modemo ('modem'), mojosa ('maneiro', 'legal', no sentido de 'bom', 'agradável' - um acrônimo de modernjunstila 'moderno, de estilo jovem', termo usado geralmente por jovens; cfr. MOJOSA, 2018). Há arbitrariedade na relação entre os planos da expressão e do conteúdo, como se pode depreender dos exemplos. As terminações, contudo, dão informação sobre as três classes gramaticais e operações morfológicas podem ser facilmente realizadas: a partir de suno ('sol') e mateno ('manhã'), pode-se ter: suna mateno ('manhã ensolarada', que também pode ser dito: mateno suna) e suno matena (ou matena suno, 'sol da manhã'). Obviamente, processos similares podem ocorrer em línguas étnicas, mas em esperanto um grande grau de regularidade foi obtido para essas três classes (substantivos, adjetivos, advérbios), bem como para o plural, cujo morfema é -j, colocado após -o ou - $a$, respectivamente em substantivos e adjetivos: sunaj matenoj ('manhãs ensolaradas').

\section{QUADRO 1 - MORFEMAS GRAMATICAIS BÁSICOS DO ESPERANTO.}

\begin{tabular}{|c|c|}
\hline$-o$ & substantivo \\
\hline$-\mathrm{a}$ & adjetivo \\
\hline$-\mathrm{e}$ & advérbio derivado \\
\hline$-\mathrm{i}$ & verbo, infinitivo \\
\hline$-\mathrm{as}$ & verbo conjugado: indicativo, presente \\
\hline$-\mathrm{is}$ & verbo conjugado: indicativo, passado \\
\hline- os & verbo conjugado: indicativo, futuro \\
\hline
\end{tabular}

FONTE: O autor (COLLING, 2015b). 
Outra importante característica é o uso de afixos. Enfoco aqui três sufixos: -ej, -il e -ar. Seus significados são, respectivamente, 'lugar', 'instrumento', 'coletivo', e alguns exemplos de uso podem ser vistos no quadro 2. Todas as palavras derivadas lá mostradas são substantivos, mas, obviamente, não há restrição ao uso de outras terminações: kuireja pordo ('porta da cozinha'), Homara Epopeo ('Epopeia da Humanidade' - título de um poema originalmente escrito em esperanto pelo autor brasileiro Sylla Chaves). Como ocorre em línguas vivas, palavras frequentemente usadas se lexicalizam, de modo que preĝejo ('igreja') refere-se não a qualquer espaço em que alguém possa rezar, mas a uma construção destinada a serviços religiosos; o mesmo ocorre com lernejo ('escola'); vortaro não é qualquer conjunto de palavras, mas significa especificamente 'dicionário'; homaro ('humanidade') inclui todos os seres humanos. Uma vez que -ej evoca um sentido bastante 'material' (ainda que seja no espaço virtual), a palavra eklezio é usada para se referir a 'igreja' como instituição e skolo é 'escola' no sentido de 'grupo de pessoas cujo trabalho ou cujas ideias são similares'. Com o passar do tempo, os afixos se tornaram independentes, de modo que ejo é uma unidade lexical; por exemplo, ejo por lerni ('lugar para estudar') tem um sentido mais amplo que lernejo. Sendo -et o sufixo para diminutivo, dometo é 'casinha'; quando traduziu $O$ pequeno príncipe, Pierre Delaire preferiu utilizar o adjetivo eta como unidade lexical: La eta princo.

QUADRO 2 - EXEMPLOS DE USO DOS SUFIXOS -EJ, -IL E - AR.

\begin{tabular}{|c|c|c|c|c|}
\hline \multicolumn{2}{|c|}{ Palavra primitiva } & Sufixo & \multicolumn{2}{|c|}{ Palavra derivada } \\
\hline cozinhar & kuiri & & kuirejo & cozinha \\
\hline rezar & preĝi & & pregejo & igreja \\
\hline $\begin{array}{l}\text { bom, agradável, legal, } \\
\text { maneiro }\end{array}$ & mojosa & $-\mathrm{ej}$ & mojosejo & $\begin{array}{l}\text { lugar agradável, onde } \\
\text { as pessoas (geralmente } \\
\text { jovens) podem se } \\
\text { encontrar e conversar; } \\
\text { pode ser também um } \\
\text { lugar virtual* }\end{array}$ \\
\hline cinema (arte) & kino & & kinejo & cinema (prédio) \\
\hline aprender & lerni & & lernejo & escola \\
\hline aprender & lerni & & lernilo & material didático \\
\hline calcular usando algoritmo & komputi & & komputilo & computador \\
\hline assistir televisão & televidi & -il & televidilo & aparelho de televisão \\
\hline cortar & tranĉi & & tranĉilo & faca \\
\hline pentear & kombi & & kombilo & pente \\
\hline palavra & vorto & & vortaro & dicionário \\
\hline árvore & arbo & & arbaro & floresta, mata \\
\hline ser humano & homo & $-a r$ & homaro & humanidade \\
\hline roda & rado & & radaro & conjunto de rodas \\
\hline
\end{tabular}

*MOJOSA, 2018.

FONTE: O autor (adaptado de COLLING, 2015b). 
Quando os computadores se tornaram populares, diferentes palavras passaram a ser usadas em esperanto: komputoro, komputatoro, ordinatoro, komputero, kompjutro, kompjutero (MONATO, 2020), mas finalmente komputilo foi amplamente aceito, por ser mais congruente com o sistema da língua. Esse sistema, entretanto, não funciona como um algoritmo a ser processado por robôs, pela adição pura e simples de -ej a cada vez que o conceito de 'lugar' está presente, ou -il para toda e qualquer ferramenta. Mais apropriadamente pode-se dizer que são recursos que os falantes têm à mão. Kombilo ('pente') e broso ('escova') têm características semelhantes, e convivem lado a lado, ainda que broso, mesmo sendo um instrumento, não faça uso do sufixo -il, e da mesma forma sobre as mesas dos esperantistas temos trancilo ('faca'), kulero ('colher') e forko ('garfo'). Se para cinema (arte) e cinema (edifício) é comum fazermos a distinção kino/ kinejo, essa distinção não é tão frequente para teatro ('teatro'), que serve tanto para a arte como para o lugar (ainda que se possa esporadicamente ouvir/ler teatrejo, forma que também é plenamente aceitável).

Vê-se aqui algum desacordo com o discurso de Zamenhof sobre logicidade e perfeição, e o esperanto foi (e às vezes ainda é) criticado por essa aparente 'falta de lógica'. Contudo, sendo falante da língua por mais de três décadas e seu usuário diário, penso que há aqui um equilíbrio entre regularidade e liberdade, que nos deixa muito à vontade (em meu caso, em um nível somente comparável ao de minha língua materna, o português). Na forma de expressão há uma região que concentra conceitos relacionados a 'lugar' (sufixo - ej), outro para 'instrumento' (sufixo -il), e assim por diante. Concentra, mas não confina. Os falantes não são obrigados a usar um raciocínio lógico estrito não precisam conhecer postulados da lógica formal -, que engessaria a língua, mas se sentem seguros para usar seus recursos quando necessário e conveniente. Há um balanço entre regularidade e flexibilidade; fosse extremamente 'lógico', o esperanto não admitiria metáforas, mas já no primeiro livro, em que Zamenhof o apresentou ao público, em 1887, incluiu poema de sua autoria (Ho, mia kor'! - 'Oh, meu coração!') em que uma metáfora se faz presente. Além disso, é possível brincar e gracejar em esperanto: na fig. 4, tem-se Mi ordonis aerŝveligi rad-aron! ('Mandei você encher os pneus!'): a confusão se instaura porque a palavra radaro pode significar 'conjunto das rodas/pneus' (rad-ar-o, no qual se usa o lexema rad-associado ao prefixo indicador de coletivo -ar, que apresentei no quadro 2), mas também pode ser 'radar' (radar-o, com o uso do lexema radar-). 


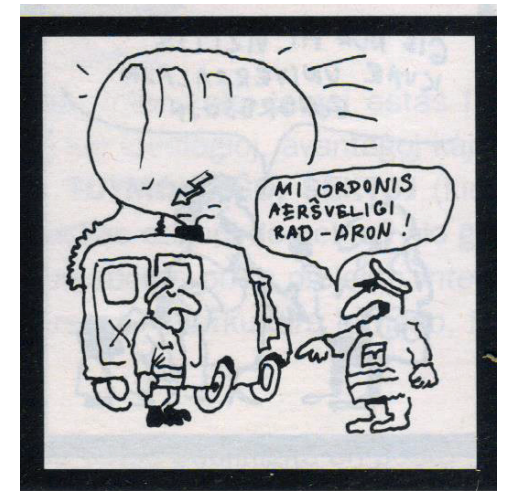

FONTE: RODGERS, 2004, p. 4.

\section{COMENTÁRIO FINAL}

Procurei mostrar ao longo do texto que ideais linguísticos e concepções do senso comum permeiam o debate na interlinguística. Em particular, penso que na maioria das vezes em que se faz alusão a logicidade, na realidade se tem em mente regularidade. A noção de mapeamento conforme entre o plano da expressão e o plano do conteúdo ilustra tentativas de 'costura' entre os planos, propostas em alguns esquemas apriorísticos. Além disso, as qualidades esperadas das línguas filosóficas, inspiradas no ideal cartesiano de permitir ver as coisas com mais clareza, consequentemente melhorando o raciocínio, estão na base do epíteto "perfeito" associado a línguas, em seu sentido de ser completo e ter contornos bem delimitados.

Na época pós-moderna, não se espera perfeição, tem-se consciência da diversidade de opiniões e rejeitam-se padrões de pensamento inflexíveis. As línguas, ainda que recebidas "como são", são continuamente co-construídas por todos os falantes, devem acompanhar o tempo e em certa medida devem representar um espaço de liberdade e espontaneidade para incentivar a criatividade. É interessante observar-se que o próprio Zamenhof tinha consciência de que o esperanto não era "dele" e confiou seu desenvolvimento à sabedoria da comunidade de falantes - já tinha clara noção daquilo que quase duas décadas depois seria afirmado por Ferdinand de Saussure (1986, p. 91) quando se refere ao esperanto.

Grande parte das características de liberdade e espontaneidade vêm justamente daquilo que eventualmente poderia ser alvo de críticas, como por exemplo a coexistência 
de um rigor nos morfemas gramaticais básicos com o fato de não se confinar todas as noções semelhantes em um único morfema, mas somente concentrá-las. Essa elasticidade permite que o esperanto em uso seja indistinguível de outras línguas étnicas, servindo também como veículo para a produção literária e artística. 


\section{REFERÊNCIAS:}

ALBANI, P.; BUONARROTI, B. Aga magéra difúra - dizionario delle lingue immaginarie. Bologna: Zanichelli, 2011.

BAGNO, M. Nada na língua é por acaso - por uma pedagogia da variação linguística. 3. ed. São Paulo: Parábola, 2009. (Educação Linguística.)

BARANDOVSKÁ-FRANK, V. Tipologio de interlingvoj kaj historio de lingvokreado ĝis Volapük. In: BARANDOVSKÁ-FRANK, V. Interlingvistiko. Cap. 5, 5p. Material do curso em linha (RITE) usado na disciplina de Interlinguística I na Universidade Adam Mickiewicz. Disponível em: <https://edukado.net/>. Acesso em 27 nov. 2011.

BARANDOVSKÁ-FRANK, V. Interlingvistiko: enkonduko en la sciencon pri planlingvoj. Poznań: Uniwersytet im. Adama Mickiewicza, Rys, 2020. No prelo.

BORGES, J. L. Del rigor en la ciencia. In: BORGES, J.L. Obras completas. Buenos Aires: Emecé, 1974. p. 847. (É parte do livro El hacedor, de 1960).

CHERPILLOD, A. L'espéranto, langue internationale, langue culturelle, mais pas 'langue artificielle'. Chosiy-le-Roi: s.n, 2006.

CHERPILLOD, A. La prétendue 'artificialité' de l'espéranto. s.n.t.

COLling, I. E. Uma discussão sobre a filosofia linguística de Descartes. Semana de Letras da UFPR. Curitiba, 28 maio - 01 jun. 2012. Anais... Curitiba: UFPR, 2012a. p. 358-371. ISSN 2237-7611. Disponível em: $<$ http://www.semanadeletras.ufpr.br/wp-content/uploads/2013/05/Semana_de_ Letras_2012_Volume2_trabalhoscompletos.pdf $>$. Acesso em 08 set. 2020.

COLling, I. E. Analizo de 'Esenco kaj estonteco de la ideo de lingvo internacia'. Grundlagenstudien aus Kybernetik und Geisteswissenschaft (GRKG), Paderborn, v. 53, n. 4, p. 183-194, Dez. 2012b.

COLLING, I. E. Kelkaj konsideroj pri logikeco, reguleco, simpleco en lingvoj (Unua parto). Grundlagenstudien aus Kybernetik und Geisteswissenschaft (GRKG), Paderborn, v. 56, n. 3, p. 109-135, Sept. 2015a.

COLLING, I. E. Languages, so fascinatingly (im)perfect, so creatively logical. Język - Komunikacja - Informacja - numer specjalny Interlingwistyka $i$ Esperantologia, Poznań, Wydawnictwo Rys, n. 10, 2015b, p. 15-31. Disponível em: $<$ http://jki.amu.edu.pl/?pl_2015-tom-x,14>. Acesso em 20 ago. 2020. 
DESCARTES, R. Euvres de Descartes. Paris: Librairie Philosophique J. Vrin, 1987. Publicação de Charles Adam e Paul Tannery. v. 1: Correspondance 1 - avril 1622 - février 1638 .

DREZEN, E. Historio de la mondolingvo - tri jarcentoj da serĉado. 4. eld. Moskvo: Progreso, 1991.

DULIĈENKO, A. En la serĉado de la mondolingvo aŭ interlingvistiko por ciuj. Trad. esperanto Aleksander Korjenkov. Kaliningrado: Sezonoj, 2006. (Scio, 7.)

ECO, U. La serĉado de la perfekta lingvo en la Eŭropa kulturo. Trad. esperanto Daniele Mistretta. Pisa: Edistudio, 1994.

FRANCINI, W. Esperanto sem preconceitos. São Paulo: Associação Paulista de Esperanto, 1976.

IEI (Internacia Esperanto-Instituto). Baza Cseh-kurso. 8. eld. Den Haag: IEI, 1992.

KOUTNY, I. Can complexity be planned? Interdisciplinary Description of Complex Systems (INDECS), Zagreb, Croatian Interdisciplinary Society, v. 13, n. 2, 2015a, p. 236249. Disponível em: <http://indecs.eu/2015/indecs_13_2.pdf>. Acesso em 07 set. 2020.

KOUTNY, I. A typological description of Esperanto as a natural language. Język - Komunikacja - Informacja - numer specjalny Interlingwistyka $i$ Esperantologia, Poznań, Wydawnictwo Rys, v. 10, 2015b, p. 43-62. Disponível em: $<$ http://jki.amu.edu.pl/?pl_2015-tom-x,14>. Acesso em 20 ago. 2020.

LARGE, A. The artificial language movement. Oxford, New York: Basil Blackwell, 1987. (The Language Library.)

LINDSTEDT,J.NativeEsperantoasatestcasefornaturallanguage.In:SUOMINEN, Mickael et alii (Ed.). A man of measure: Festschrift in honour of Fred Karlsson on his 60th birthday. Suplemento especial de SKY Journal of Linguistics, Turku, v. 19, 2006. Disponível em: $<$ http://www.linguistics.fi/julkaisut/SKY2006_1/1FK60.1.5.LINDSTEDT.pdf $>$. Acesso em 07 set. 2020.

LOCKE, J. An essay concerning human understanding. New York; Melbourne: Ward, Lock, 1890.

MAAT, J. Philosophical languages in the seventeenth century: Dalgarno, Wilkins, Leibniz. Dordrecht: Kluwer Academic, 2004. 
MATTHIAS, U. Esperanto: o novo latim da Igreja e do ecumenismo. Trad. port. Ismael M.A. Ávila. Campinas: Pontes, Sorocaba: BEKO, 2003.

MASSON, H. Oriento-Okcidento/Nordo-Sudo: programita fremdigo. Rev. 20 jul. 2008. Disponível em: <https://www.sat-amikaro.org/oriento-okcidento-nordo-sudoprogramita-fremdigo?lang=fr $>$. Acesso em 06 set. 2020.

MOJOSA. In: ReVo - Reta Vortaro, verbete atualizado em 02 set. 2018. Disponível em: $<\mathrm{http}: / /$ www.reta-vortaro.de/revo/>. Acesso em 11 set. 2020.

MONATO. Monato-konvencioj. Pág. atualizada em: 02 set. 2020. Disponível em: $<$ https://www.monato.be/konvencioj.php>. Acesso em 11 set. 2020.

PASSINI, J. Bilinguismo: utopia ou solução? 3. ed. Campinas: Pontes, 2008.

PAULI, E. Pelo esperanto com estratégia. In: PAULI, Evaldo et alii. Não só idealistas, mas realizadores - coletânea de depoimentos de esperantistas. São Paulo: Liney, 1995. p. 101-118.

PICANÇO, D. C. de L. História, memória e ensino de espanhol (1942-1990). Curitiba: Universidade Federal do Paraná, 2003.

PIRON, C. O desafio das línguas: da má gestão ao bom senso. Campinas: s.n., 2007. Trad. port. Ismael Mattos Andrade Ávila. Disponível em: <https://social.stoa.usp.br/ articles/0015/3750/desafiodaslinguas.pdf $>$. Acesso em 07 set. 2020.

PORFIRIO la Fenica. Enkonduko en la kategoriojn de Aristotelo. Chapecó: Fonto, 1983. (Klasikuloj de la Filozofio). O livro contém comentários do Prof. Evaldo Pauli (p. 1-34) e a tradução do texto ao esperanto por Pauli (p. 35-79).

RODGERS, D. Humuro en Esperanto, Kontakto, Rotterdam, n. 200 (2004:2), p. 3-5.

ROSENFELDER, M. Advanced language construction. Chicago: Yonagu, 2012.

SAUSSURE, F. de. Curso de linguística geral. 12.ed. São Paulo: Cultrix, 1986.

SPIEGEL, M. R. Complex variables with an introduction to conformal mapping and its applications. New York: Schaum, 1964.

STRIA, I. Esperanto as a natural language. Język - Komunikacja - Informacja - numer specjalny Interlingwistyka i Esperantologia, Poznań, Wydawnictwo Rys, n. 10, 2015b, p. 32-42. Disponível em: <http://jki.amu.edu.pl/?pl_2015-tom-x,14>. Acesso em 20 ago. 2020. 
WITTGENSTEIN, L. Tractatus logico-philosophicus. Texto bilíngue (alemão português), trad. port. Luiz Henrique Lopes dos Santos. 3. ed., 2. reimpr. São Paulo: Universidade de São Paulo, 2010.

ZAMENHOF, L.L. Dua libro de l' lingvo internacia. Varsovio: Chaim Kelter, 1888. Inclui o suplemento Aldono al la 'Dua libro de l' lingvo internacia'. Disponível em: <http://esperanto.davidgsimpson.com/librejo/DuaLibro.pdf>. Acesso em 07 set. 2020. (O mesmo texto, com outra formatação, também está disponível em: $<$ https://www.gutenberg.org/ebooks/20006>).

ZAMENHOF, L.L. Essência e futuro da ideia de uma língua internacional. Goiânia: Zamenhof, 1988. (Língua Internacional, 1).

ZILAH, E. de. Letero de Kartezio pri Lingvo Internacia. Filozofia Revuo Simpozio, Florianópolis, v. 1, n. 1, p. 11-16, Marto 1983. (Tradução da carta de Descartes em esperanto: p.11-13; comentários de Zilah: p. 14-16). 